\title{
DESVENDANDO MÚLTIPLAS MÁSCARAS DO JOGO SOCIAL NO MUNDO VIRTUAL: ESTUDO ANTROPOLÓGICO SOBRE O FENÔMENO DO ORKUT
}

André Sarmento

Cornelia Eckert (orientação)

Com o advento da rede mundial de computadores, ou internet, concretizou-se uma nova dimensão de sociabilidade: o ciberespaço. Este novo espaço de sociabilidade gera novas formas de relações sociais, com códigos e estruturas próprias. A experiência de alteridade no seu interior é vivida de maneira bastante intensa através dos "ambientes de sociabilidade virtual" e das comunidades virtuais.

Georg Simmel (1967) caracterizou a situação do indivíduo na sociedade moderna como ponto de interseção de vários mundos. $\mathrm{O}$ reconhecimento da diferença como elemento construtivo da sociedade, não só o conflito, mas a troca, a aliança e a interação em geral, constituem a própria vida social através da experiência, da troca e do reconhecimento explícito ou implícito de interesses e valores diferentes. Portanto, pode-se afirmar que os ambientes virtuais promovem a troca entre indivíduos e, assim, proliferam-se pela internet grupos de discussão, salas de bate-papo virtual, fóruns de assuntos específicos, listas de contato para troca de mensagens, entre outros. Ao entendermos o Ciberespaço como um espaço de sociabilidade que está longe de ser um local homogêneo oferecendo-nos um cenário, bastante semelhante ao das sociedades complexas contemporâneas podemos nos apoderar deste referencial teórico para entendermos o novo mundo que está saltando aos nossos olhos.

O tema do fenômeno das novas tecnologias não pode ser desvinculado das teorias sobre a sociedade moderna, sobre a ação no contexto urbano, sobre a dinâmica da globalização, sobre a sociabilidade e redes sociais nos grupos contemporâneos.

\section{Novos conceitos para novos contextos}

Analisando as transformações pelas qual a sociedade contemporânea está passando, Castells (1999) nos fala que o capitalismo passa por um processo de profunda reestruturação 
que implica em novas formas de relações de trabalho, novas sociabilidades, reestruturação de valores sociais e culturais.

A origem desta mudança está na revolução tecnológica que surge nos EUA, na década de 1970, a partir da sinergia de uma série de fatores. Esta revolução cria um novo modo produtivo: o informacional, que permitirá a reestruturação do capitalismo. A revolução tecnológica suscita o surgimento da sociedade informacional ou "sociedade da informação".

$\mathrm{Na}$ sociedade da informação e suas múltiplas possibilidades de conexão em redes virtuais, o uso disseminado do computador, o acesso às informações, a universalização dos meios de comunicação e telecomunicações, conjugados com a expansão da internet no mundo, possibilitam o surgimento de um novo espaço de comunicação e sociabilidade: o "ciberespaço", e de uma cultura específica: a "cibercultura", entendida como um "conjunto de técnicas, práticas, modos de pensamento e valores que se desenvolvem junto com um novo espaço de comunicação, o ciberespaço”. (ABRANTES, [200-], on-line).

A origem do termo ciberespaço data do ano de 1984, quando o escritor norte americano William Gibson define o termo no livro Neuromancer, em um ambiente de ficção. Hoje, o termo pode ser trazido para a realidade e entendido como resultante da interconexão mundial de computadores. O conjunto da infra-estrutura material, das informações circulantes, e das pessoas que utilizam, usufruem, ao mesmo tempo em que constituem esse conjunto.

O ciberespaço pode ainda ser entendido como um imenso território em expansão acelerada. $\mathrm{O}$ acesso à internet é crescente. A expansão do uso individual de computadores vem de um movimento social que coloca a técnica próxima ao indivíduo. É importante frisar que não apenas a internet é a formadora do ciberespaço (apesar de ser o principal), mas também telefones celulares, redes independentes, associações, universidades e até mídias clássicas (telefone, televisão e rádios), além dos próprios indivíduos são componentes deste novo "ambiente".

O conceito mais importante desenvolvido por Pierre Levy, em seu livro Cibercultura (1999), é o de que a rede de computadores é um universal sem totalidade, ou seja, que ela permite às pessoas conectadas construir e partilhar a inteligência coletiva sem submeter-se a qualquer tipo de restrição político-ideológica. Partindo deste princípio, Levy encara a internet como um agente humanizador (porque democratiza a informação) e humanitário (porque permite a valorização das competências individuais e a defesa dos interesses das minorias). $\mathrm{O}$ 
autor procura demonstrar que a internet traz benefícios para a espécie humana. Levy dedicase à desconstrução dos mitos criados pelos críticos da rede que não foram capazes de perceber o potencial humanizador e humanitário da era high tech ${ }^{l}$.

As implicações sócio-políticas da rede de computadores, ou seja, do ciberespaço, não passaram despercebidas de Levy, que nos dá uma clara dimensão do potencial educacional e desinstitucionalizador da internet. Conectado, o cidadão tem condições de interferir diretamente no controle das decisões públicas sem mediadores, algo que pode ajudar a descentralizar, democratizar e otimizar os serviços públicos. Apesar de defender as vantagens da vida on-line $^{2}$, Pierre Levy não comete o erro de afirmar que a conecção substitui ou substituirá a interação social, o contato entre as pessoas. Ao contrário, segundo o autor a internet possibilita contatos mais freqüentes e produtivos na medida em que aproxima os atores sociais antes mesmo dos acontecimentos coletivos. Nesse sentido, o ciberespaço (assim como o correio e o telefone) não é um agente de desumanização ou de isolamento do ser humano.

Pierre Levy não perde de vista a profunda relação de dependência entre a era high-tech e a história da evolução das comunicações entre os seres humanos. Da oralidade aos e-mails a humanidade desenvolveu sistemas de comunicação que coexistem e são mutuamente dependentes. Assim como a escrita pressupõe a linguagem oral que descreve e normatiza, mas não foi capaz de substituí-la, o armazenamento e transmissão de textos on-line dependem da escrita e não irão condená-la ao esquecimento, mesmo que doravante esteja mais do que nunca associada à imagem. A rede não somente valoriza a comunicação escrita, como a torna mais eficiente, na medida em que possibilita a navegação entre textos afins instantaneamente.

Levy faz uma analogia entre a oralidade original e a reorientada pela era digital, que retira de cena os mediadores no processo de comunicação escrita (jornais, revistas, televisão, ou seja, as mídias que permitem a comunicação um-todos) e possibilita a comunicação direta e transversal (todos-todos). A cibercultura caracteriza-se essencialmente pela conexão entre as pessoas e a comunicação é a sua formadora maior.

O ciberespaço, ao constituir-se em um novo ambiente de sociabilidade, acaba gerando outras formas de relações sociais, com códigos e estruturas próprias, a experiência de

\footnotetext{
${ }^{1}$ Alta tecnologia.

${ }^{2} \mathrm{O}$ emprego dos termos on-line e off-line neste trabalho é: on-line = dentro do ciberespaço e off-line $=$ fora do ciberespaço.
} 
alteridade $^{3}$ no seu interior é vivida de maneira bastante intensa através dos "ambientes de sociabilidade virtual" e das comunidades virtuais. O antropólogo Mário Guimarães Júnior estabelece, neste interim, uma distinção entre "ambientes de sociabilidade virtual" e "comunidades virtuais", "com o intuito de reservar esta categoria para as circunstâncias onde tais elementos denotativos de comunidade efetivamente compareçam” (GUIMARÃES JR., 1998, on-line). Segundo o autor:

[...] caracterizo como "ambiente de sociabilidade" o locus criado no ciberespaço por programas específicos orientados à comunicação de dois ou mais usuários, que é povoado por indivíduos que estabelecem uma atividade societária por um determinado tempo. A partir desta sociabilidade podem se desenvolver comunidades virtuais estáveis, que irão abrir mão dos mais variados recursos disponíveis para veicular esta sociabilidade. As comunidades virtuais não estão necessariamente associadas à apenas um ambiente, mas sim às relações entre seus integrantes. (GUIMARÃES JR., 1998, on-line).

As comunidades virtuais se formam independentemente dos aspectos institucionais ou geográficos, o princípio básico é a afinidade de interesses ou objetivos. A integração em uma comunidade virtual é precedida pelo conhecimento do grupo e reconhecimento deste para com o integrante. Neste ponto, permanece a necessidade de ser reconhecido nos grupos existentes nas comunidades terrestres, ou melhor, naquelas que estão próximas fisicamente. As regras nas comunidades virtuais vão surgindo devido à participação constante de cada componente e se firmam com a adesão de cada um. Resultante do conjunto das relações técnicas, práticas, atitudes, pensamentos e valores desenvolvidos com o crescimento do ciberespaço.

O sociólogo francês Michel Maffesoli - em O tempo das tribos - permite que interpretemos estas comunidades como redes de comunicação, onde o sentimento de "pertença” a um espaço simbólico é o fator fundamental da constituição das comunidades virtuais conforme o próprio autor: “[...] a constituição dos microgrupos, das tribos que pontuam a espacialidade se faz a partir do sentimento de pertença, em função de uma ética específica e no quadro de uma rede de comunicação. [...]” (MAFFESOLI,1987, p. 194). Este espaço exige de seus integrantes uma atuação distinta uma performance diferenciada em relação as outras esferas de sociabilidade.

Conforme Guimarães Jr. (1999), uma das questões freqüentes na literatura sobre cibercultura é a que diz respeito ao status do informante. Quem é o ator social no ciberespaço,

\footnotetext{
${ }^{3}$ Fato ou estado de ser Outro; diferição do sujeito em relação a um outro. Opõe-se a identidade, mundo interior e subjectividade. (CEIA, 2005, on-line).
} 
o indivíduo que senta à frente de seu computador ou as personas ${ }^{4}$ que esse indivíduo vive? Se um único indivíduo pode ser múltiplas personas como saberemos o que é mentira ou não? $\mathrm{O}$ autor nos responde assim:

A Antropologia não está necessariamente preocupada com as pessoas enquanto indivíduos, mas sim enquanto sujeitos de relações sociais no contexto sob estudo. Desta forma, de acordo com o objeto de estudo e o recorte empírico adotado, os informantes de uma "Ciberantropologia" - ou Antropologia feita no Ciberespaço - tendem a ser mais as personas que os sujeitos por trás dos teclados. Não é possível afirmar a existência de uma relação unívoca entre uma persona e uma pessoa física - da mesma forma que um sujeito, em sociedades complexas, pode pertencer a diferentes grupos - na medida em que o mesmo sujeito pode viver, em contextos diversos, vários avatares distintos. A intenção de encontrar a "verdade" por trás das máscaras sociais deve ser descartada a princípio, sob risco de perderse nessa busca a riqueza intrínseca da sociabilidade criada e atualizada no nível das máscaras. (GUIMARÃES JR., 2000, p. 18).

Nesta pesquisa, considerei como informantes predominantemente, porém não exclusivamente, as personas. Naturalmente, não foram ignoradas as pessoas "físicas" existentes por trás destas personas, mas o foco empírico e analítico estará baseado no conceito de footing, de Erving Goffman (1998), que o usa para definir a performance de desempenho das identidades sociais e lingüísticas dos participantes de um interação face a face, neste trabalho ficará centrado nas interações e performances dos usuários do site de relacionamentos Orkut.

As redes de comunicação surgem via exercício de alteridade praticado por seus usuários no Orkut, o que acontece por meio da criação do perfil pessoal. Para um melhor entendimento do leitor, explico desde já que no Orkut existem dois tipos de perfil: o que denomino "original" é aquele perfil dito "verdadeiro", ou seja, reconhecido pelo senso comum como sendo de uma pessoa "real" e o perfil fake, aquele que é tratado pelo senso comum como "falso". Partindo da premissa que todos os perfis são construídos pelo usuário, todos, sem distinção são personagens (personas), construções sociais, representações dos usuários no "bom" e "velho" sentido proposto pelo pai da Sociologia, Emile Durkheim, e seu herdeiro fundador da Antropologia Social, Marcel Mauss. Estas máscaras sociais, para atuarem no ciberespaço, precisam de representação. Pensemos em avatar como aquilo que nos representa em determinado contexto. No ciberespaço nos utilizamos dos avatares para

\footnotetext{
${ }^{4}$ Desenvolverei este conceito no próximo capítulo.
} 
podermos atuar dentro deste novo ambiente de sociabilidade. O Orkut possibilita a criação de avatares que agem como a corporificação da persona no ciberespaço.

Conforme Marcel Mauss (1974), na antiguidade, persona era a designação de máscara como a que os atores do teatro romano usavam. Sua função era tanto dar ao ator a aparência que o papel exigia quanto amplificar sua voz, permitindo que fosse bem ouvida pelos espectadores. A palavra é derivada do verbo personare, ou "soar através de". Por extensão, designa um papel social, ou um papel interpretado por um ator social.

Na psicologia analítica, em geral associada a Jung, a persona é a máscara ou aparência que uma pessoa apresenta ao mundo. O conceito de persona que utilizo é o mesmo de Mário Guimarães Jr. (2000) que em seu trabalho de mestrado recorre a Richard MacKinnon, autor de Searching for the Leviathan in Usenet, de 1995. Este autor emprega persona para designar as identidades construídas pelas pessoas no interior do ciberespaço. Em Erwing Goffman (1975), cada pessoa, se veste de uma persona, e essa persona, por sua vez, deve revelar um eu apropriado para cada ocasião e, ao mesmo tempo, esconder um self que, se revelado, poderia inibir, embaraçar ou distorcer o seu propósito. Segundo o autor, todo ser humano é ciente dessa personificação, mas, de qualquer forma, a meta última dos dramas naturalistas representados no teatro da vida é desvendar o drama escondido, e os atores reais, no teatro secreto da mente.

\section{As comunidades virtuais e seus integrantes}

As comunidades virtuais ou tribos virtuais, assim como as tribos urbanas ${ }^{5}$, possuem suas próprias características e identidades ${ }^{6}$, que vão diferenciá-los entre si, pelas suas ideologias, atitudes e práticas dentro do ciberespaço. Este está longe de ser um lugar homogêneo, mas pode-se constatar que existe no nível do senso comum da população com acesso aos meios de comunicação de novas tecnologias a noção de que o ciberespaço é povoado única e exclusivamente por Hackers. Conforme Lemos (2004), o ciberespaço é povoado por diferentes tribos virtuais, entre elas estão: Phreakers, Crackers, Cypherpunks, Ravers, Zippies, Cyberpunks, Defacers entre outros.

\footnotetext{
5 Maffesoli (1987) e Costa (2001) denominam de "tribos urbanas", grupos formados principalmente por adolescentes e jovens que nas cidades, sobretudo nas grandes, são chamados de turmas, galeras, comandos, bandos ou quadrilhas que dominam regiões, sendo temidos quando agressivos. Dentre essas tribos se encontram os Punks, Hippies, Skinheads, Surfistas e Mauricinhos.

${ }^{6}$ Identidade em relação à noção de pertencimento, de permanência em algo. De identificação e afinidade.
} 
O que diferencia uma tribo virtual das outras é o exercício das atuações de diferentes papéis e performances, que implica em múltiplas alteridades, e pluralidade de formas de jogar no social. Um ciberpunk não precisa ser um ciberpunk em todos os momentos de sua vida, como por exemplo, um punk que é um punk em qualquer lugar que vá a qualquer hora, mas ao entrar no ciberespaço este mesmo punk pode ser quem quiser e até pertencer a qualquer outra tribo. Um executivo de meia idade pode ser surfista aos fins de semana e na rede ser um ciberpunk, uma dona de casa de quarenta anos, com dois ou três filhos, ao entrar na internet, pode ser um guerreiro medieval da corte de um reino qualquer. As pessoas, ao entrarem na rede, podem representar papéis e mudar o seu figurino conforme seus gostos e momentos, tendo a chance de participar de quantas tribos desejarem. Para Gilberto Velho (1994), em seus estudos sobre grupos urbanos, esta é uma característica das redes sociais em sociedades complexas, o que seria para ele, as metamorfoses de atuar nas redes de significado. (GEERTZ, 1973, apud VELHO, 1994).

Estas metamorfoses sugerem um exercício da alteridade. No site de relacionamentos Orkut passa pela criação de um ou mais perfis, por parte do usuário. Cada perfil criado é um personagem uma persona a interagir no ambiente, cada qual com suas características e com um avatar próprio a representá-lo.

No Orkut, o usuário pode fazer um perfil com seus dados ditos "verdadeiros", ou melhor, o mais fiel possível a sua pessoa física, mas mesmo que esse perfil seja reconhecido pelo senso comum como "verdadeiro" ou "real" ele será mesmo assim uma persona criada para representá-lo no ciberespaço, pois, mesmo que o usuário diga que não mentiu em nenhuma das afirmações que colocou ao preencher o perfil e que seus pares confirmem isso, assim mesmo será uma construção de uma persona porque, ele pode não ter mentido, mas criou um personagem, que lhe represente, que pode omitir alguma coisa dele que ele não quer que apareça mesmo que isso não seja consciente. Joga-se com as imagens possíveis no social, manipula-se representações simbólicas, constroi-se performances e perfis. Entre o brincar e o interpretar, algumas representações são inconscientes. Para Guimarães Jr., "tanto para falsear e simular um personagem quanto para ser 'sincero', o indivíduo terá que manipular as regras e códigos do ambiente, revelando assim a dinâmica cultural do mesmo". (GUIMARÃES JR., 1999, on-line).

Para o senso comum, ter um perfil "real" no Orkut é quando o usuário coloca todas as informações corretas a seu respeito, seu nome, seu e-mail, endereço, foto e tudo conforme o considerado por seus próximos como verdadeiro e irrefutável, isso é prova da existência desta 
pessoa quando outras pessoas confirmam sua existência física off-line. Mas o real é o social e todos estão todo o tempo representado papéis diferentes o tempo todo, dependendo apenas do espaço de sociabilidade em que estão. Somos alunos na faculdade, professores na escola de ensino médio, pais em nossa casa e filhos na casa de nossos pais, homens e mulheres e tudo isso ao mesmo tempo. No ciberespaço como sendo apenas mais um espaço de sociabilidade temos um ou mais papéis para representar com uma diferença, podemos escolher quem queremos ser.

Por isso, construímos personas que encarnamos através dos avatares e assim podemos tentar ser apenas nós mesmos ou sermos "realmente" um dinossauro comedor de quindim que distribui poemas subversivos na página de recados dos usuários do Orkut. Utilizando-me de uma metáfora já consagrada nas ciências sociais e devido a suas características podemos considerar o site Orkut um imenso baile de máscaras onde os avatares bailam intensamente.

Diversas mitologias nos contam que os deuses utilizavam avatares para atuar em nosso universo. No hinduísmo, um avatar é uma manifestação corporal de um ser imortal, por vezes até do Ser Supremo. Deriva do sânscrito Avatāra, que significa "descida", normalmente denotando uma descida deliberada para o reino dos mortais com intenções específicas. $\mathrm{O}$ termo é usado primariamente para encarnações de Vishnu (tais como Krishna), que muitos hinduístas reverenciam como Deus. Segundo o hinduísmo, Vishnu vem ao mundo de diversas formas, chamadas Avatares, que podem ser humanas, animais ou uma combinação dos dois.

O avatar no ciberespaço, conforme o site do Wikipédia $^{7}$ é a representação gráfica de um usuário em realidade virtual, jogos, ou outros ambientes interativos como fóruns e batepapos. De acordo com a tecnologia, pode variar de um sofisticado modelo 3D (em três dimensões) até um simples ícone. (WIKIPÉDIA, 2005, on-line).

Tomamos os avatares no site de relacionamentos Orkut, como sendo a representação da persona, ou seja, o perfil criado pelo usuário. Lá estão descritas todas as características físicas e representativas dele, sua família seus amigos, escolas que estudou, local onde trabalha enfim cada perfil é único como seu criador.

\footnotetext{
7 A Wikipédia é uma enciclopédia livre baseada em wiki e escrita por voluntários. Livre aqui significa que qualquer artigo da Wikipédia pode ser copiado e modificado desde que os direitos de cópia e modificação sejam preservados. O conteúdo da Wikipédia está sob licença GNU FDL(GNU Free Documentation License é uma licença para documentos e textos livres publicada pela Free Software Foundation.)
} 
Ao navegarmos pelos perfis dos usuários, vemos que a presença de jovens é esmagadora. Pode-se constatar que existe um padrão estético culturalmente orientado pelos padrões ocidentais de aparência, nas fotos dos usuários.

A maioria dessas fotos obedece a uma representação estereotipada de um adolescente ocidental contemporâneo, que é adotado por uns e negada por outros. O que se esboça é uma escolha implícita do visual que identifica um grupo, uma "turma" de pertencimento urbano, classe média, com poder aquisitivo de consumo minimamente médio, com estilo de vida moderno, para recorrer a Gilberto Velho (2000) ao mostrar que no Brasil o desenvolvimento da cultura de massas introduziu temas e linguagens que foram absorvidos de modos distintos pelos diferentes segmentos da população, mas criou referencias comuns como por exemplo, jovens de classe popular demandando bens de consumo próprios da classe média alta como vestuário e calçados de griffe.

Este estilo, esta performance é adotada por aqueles que pretendem estar de acordo com as "regras do jogo". No sentido de Goffman, regras de representar-se na performance sem perder "a pose". Para Maffesoli (1987) os "padrões estéticos" adotados pelos indivíduos são fatores de agregação e/ou diferenciação entre os grupos urbanos.

A princípio, temos um padrão de visibilidade positiva buscada pelo usuário, como falou Claudiane, uma de minhas entrevistadas, a respeito de sua foto:

- coloquei esta imagem (foto de um animal selvagem), porque estava sem uma foto boa, só tenho fotos que estou muito nada, há, vê, sabe né, nenhuma que eu esteja bonita assim “deslumbrante”. E também, porque me identifico com esta coisa meio selvagem, não gosto de coisas muito fofinhas tipo gatinhos e cachorrinhos, todos queremos aparecer bonitos, afinal aqui (o Orkut) é o nosso $B B B^{8}$.

Para esta usuária entrevistada, Claudiane, o fluxo constante de gente interessada em saber da vida dos outros é o que dá graça ao Orkut, Para os usuários como esta entrevistada, é preciso estar deslumbrante estar bela, bonita, estar "bem na foto", pois, - Ao menos aqui (no Orkut) todos estão vendo a gente. Completa Claudiane. O Orkut é tratado por ela como um espaço de evidência, que pode gerar um espaço de espetáculo e sensação de fama. Para Maffesoli “[...] é preciso fazer-se ver e ser visto para existir. Só se existe no, e pelo, olhar do outro, donde a importância dos corpos em exibição, de suas metamorfoses e mesmo de suas

\footnotetext{
${ }^{8}$ Quando ela fala “BBB” ela se referiu ao Big Brother Brasil, programa da rede Globo de Televisão.
} 
mutações”. (MAFFESOLI, 2000, p. 46). Não se trata de uma invasão a privacidade, pois o jogo implica em mostrar-se, ser visto e consumido.

A noção de corpo está aqui em destaque. Michel Foucault (2001) teoriza a noção de corpo como expressão de poderes e de saberes que se articulam estrategicamente na história da sociedade ocidental. O corpo é, simultaneamente, agente e peça dentro de um jogo de forças presente em toda a rede social, que o torna depositário de marcas e de sinais que nele se inscrevem nesses embates, os quais, por sua vez, têm na corporeidade seu "campo de prova" (SILVEIRA; FURLAN, 2005).

A cultura de consumo denunciada por Michel Foucault em sua obra intitulada História da sexualidade $(1985,2001)$ estimula um estilo de vida que privilegia o supérfluo onde o corpo tornou-se um símbolo, um objeto do desejo e com ele o consumo da "imagem" virou compulsão: tudo gira em torno do corpo e sua representação.

A idéia, ou melhor, o conceito de beleza é estreita e socialmente construída. Conseqüentemente a sensualidade ou sexualidade que o mundo da mídia cria na verdade é um mecanismo social, político e econômico para controlar o comportamento social e sexual das pessoas inseridas nesta sociedade. (SAYÃO; BOCK, 2002). A divulgação repetitiva pela mídia de corpos magros, longilíneos, esbeltos, de pele branca, cabelos loiros e olhos azuis, associada a uma cultura de consumista, de forma latente ou explícita, promove uma idealização desse tipo físico corporal, relacionando-o aos ideais de beleza, saúde, felicidade e ao poder de atração sexual.

Nesta pesquisa, aponta-se que na medida em que o usuário não se adequa a estes modelos ideais, usa avatares do tipo ícone, evitando fotos. Isto por que os modelos - cujo padrão estético não corresponde ao tipo físico apresentado como ideal pela mídia - podem contribuir para a construção de uma auto-imagem negativa para aqueles que não se enquadram nesse padrão veiculado pelas propagandas. As pessoas podem se sentir excluídas nas possibilidades de auto-aceitação e auto-cuidado, quesitos básicos para a busca de prazer e felicidade nas relações sociais.

Os usuários do Orkut - orientados pelo padrão ocidental de corpo - estão projetando estes padrões de beleza por meio de avatares (fotos, ícones e imagens), dando visibilidade

\footnotetext{
${ }^{9}$ Em $O$ cuidado de si, Foucault coloca que a cultura de si é um dos princípios de poder, onde os sujeitos são incentivados a "ter cuidados consigo" visando transformação/correção, purificação e salvação. O cuidado de si seria, portanto uma forma de poder que "estimularia" os sujeitos a controlar e a conhecer seu próprio corpo para uma vivência mais regrada deste. (FOUCAULT, 1985)
} 
para um corpo que se projeta enquanto uma extensão do corpo físico. Augusto falando-me que semanalmente troca sua foto no Orkut, diz: - Estou malhando e quero que todos vejam que estou crescendo ${ }^{10}$. Augusto sempre coloca fotos em que aparece sem camisa e com uma postura que realça os bíceps.

Outro grupo de usuários pode ser caracterizado como tendo um estilo de crítica a esta padronização. Temos no Orkut grupos que negam um modelo dominante de beleza e fazem de tudo para não aparecer com uma foto feita em estúdio fotográfico. Angélica sempre coloca fotos com efeitos e produções caseiras que realçam seu estilo mais "Dark ${ }^{11}$ ", ela e o namorado aparecem juntos nas fotos tanto do perfil dela quanto do dele, perguntei o porquê disso e qual a proposta deles para as fotos que colocaram, - Botamos as fotos juntos porque estamos sempre juntos o namorado interrompe e fala: - Não somos como aqueles “manés ${ }^{12}$ ", eles podem falar o que quiserem de nós, mas não nos vendemos para a modinha escrota deles. Angélica completa: - Não preciso ser "pati"13” para ser bonita, eu sou bonita por que sou original não preciso pôr nenhuma foto de "book" para ser bonita. Mesmo negando o padrão de beleza dominante, para Angélica ela está bonita na foto que usou no Orkut, para ela e o namorado "eles estão bem na foto". Não importa se o usuário está reproduzindo o modelo de beleza dominante ou negando-o e utilizando-se de um modelo oposto ou alternativo de beleza, mas todos acabam por projetar no avatar um determinado modelo de pessoa, realçando determinadas posturas que são tidas como positivas pelo usuário.

Estas projeções são orientadas culturalmente, portanto, estão incluídas, na construção dos avatares, as dimensões da aprendizagem e todas as potencialidades do indivíduo de se apropriar de suas vivências. Isto significa que é por meio do corpo que podemos compreender o modo particular como cada um organiza e sente tudo o que vive, atribuindo sentido a cada experiência. "A capacidade de emitir sons, por exemplo, depende de condições anatômicas enquanto que a linguagem é uma forma de articular sons e significados que tem de ser aprendida" (SAYÃO; BOCK, 2002, on-line).

A cultura se exerce necessariamente no e pelo corpo, influenciando-o e moldando-o. Por sua vez o corpo se forma necessariamente na e pela cultura, influciando-a e moldando-a, e quanto mais tecnologia a disposição das pessoas maior a interação entre elas.

\footnotetext{
${ }^{10}$ Crescendo no sentido de ficando musculoso.

${ }^{11}$ O movimento Dark surgiu nos anos 1980, com a banda The Cure onde todos se vestem de preto e cultuam um visual mais alterantivo se opondo ao padrão imposto pela mídia.

${ }^{12}$ Gíria que quer dizer otários.

${ }^{13}$ Redutivo de "patricinha" que é aquela menina que está sempre na moda.
} 


\section{Especulações de um futuro próximo}

O Orkut, em relação às tecnologias que estão sendo produzidas, já está ultrapassado. O Second Life Está aí para nos provar isso. Como o próprio nome diz "segunda vida", o Second Life é um ambiente virtual, tridimensional que simula em muitos aspectos a vida "real", ou seja, tenta ser o mais próximo do off-line possível. Ele pode ser encarado como um jogo, um mero simulador, um comércio virtual ou uma rede social. O diferencial do deste ambiente é a infinidade de formas pelas quais os usuários concebem suas personas e avatares (que se movimentam dentro do metaverso ${ }^{14}$ ), e neste processo constroem uma rede de troca de comunicações com aspectos "reais". Por exemplo, é possível um grupo de amigos se encontrarem num bar qualquer dentro do metaverso e travarem uma discussão tal qual estivessem reunidos no bar que freqüentam aqui fora no off-line. Isto é apenas o primeiro passo.

A adoção de um avatar "mimético" possibilitará tornar mais "real" a comunicação feita a distância. Conforme Farias e Cantone (2002), as relações sociais via ciberespaço serão realizadas num ambiente virtual o mais real possível. A proposta dos desenvolvedores de tecnologia é inserir, no lugar dos programas de mensagens instantâneas do tipo msn e ICQ, em que no máximo o usuário coloca uma foto sua para identificar-se, por um programa no qual o usuário digitalizará a imagem do próprio corpo para criar um avatar idêntico ao corpo real e interagir com seus amigos num ambiente holográfico ${ }^{15}$. O usuário vestirá uma roupa especial que reproduzirá todos seus movimentos dentro do ciberespaço, o usuário sentará à frente do seu computador, mas estará numa ilha do pacífico ou sentado em frente às pirâmides do Egito, por exemplo, conversando com seus amigos. Ao mesmo tempo, é possível a incorporação no ciberespaço de "corpos" diferentes do corpo "real" do usuário, que possibilitarão vivências sociais diversas daquelas que lhe são normalmente possíveis, dando vazão a desejos (crianças que atuam como adultos, anônimos que atuam como celebridades, pobres que atuam como ricos, homens que atuam como mulheres e vice-versa, etc).

Conforme Guimarães Jr.:

\footnotetext{
${ }^{14}$ Metaverso é qualquer universo "virtual" dentro do universo "real".

15 Holografias são ambientes virtuais em que pessoas podem caminhar, mexer nos objetos e interferir nas histórias, tecnologia muito utilizada no cinema. Para criar um ambiente assim é preciso uma sala onde as paredes são pintadas com uma tinta especial de cor verde que será projetada a holografia, os usuários tem que utilizar óculos e roupas especiais.
} 
No Ciberespaço nos deparamos com uma capacidade metamórfica hiperbólica, extremamente rápida, eficaz e dissimulada, onde o indivíduo busca se adequar ao contexto do grupo onde está inserido. Em um mesmo momento de vivência on-line, o mesmo indivíduo "real" pode estar dando vida a diferentes sujeitos virtuais, cada um deles em um ambiente diferente, exigindo máscaras distintas. No entanto, no interior de cada contexto de sociabilidade virtual, percebese a existência de um frame básico, dentro do qual a variabilidade das mudanças encontra-se restringida. [...] a contemporaneidade oferece ao homem um leque de recursos nunca antes visto em termos de possibilidade (e, no caso, exigência) de criação de códigos comunicativos (entendidos, aqui, como sistemas culturais). Cada indivíduo, por sua vez, relaciona-se em seu cotidiano com diferentes comunidades de sentido, habita, simbolicamente, diferentes tribos. Mesmo em sua vivência Ciberespacial, os códigos, estruturas, temas, enfim, o conjunto inteiro de seu self presentation varia de acordo com o grupo. [...]. (GUIMARÃES JR., 1999b, on-line).

No ciberespaço trabalhamos com todas as possibilidades, nada é descartado. Este exercício de alteridade que a internet nos possibilita é amplamente utilizado no Orkut ,como nos mostram os Fakes.

\section{Os Fakes}

Fakes ou bogus são os perfis "falsos" criados no Orkut com alguns possíveis objetivos, discutirem política sem comprometimento; ou para difundir conteúdo ilegal, como racismo, pedofilia etc; ou fazer uma brincadeira, por exemplo: criar o perfil de uma celebridade como Madonna, Roberto Justus, o presidente Lula entre outros; possibilitar anonimato, ou seja, ter uma navegação dentro do site com o objetivo de proteger sua privacidade; visualizar quem viu o seu perfil oficial, sem precisar deixar marcado no perfil do outro que retornou a visita. Parte desses fakes tem orientação política anarquista, existe uma quantidade considerável de comunidades anarquistas, como se autodenominam os usuários. De modo geral, sua característica principal é fazer "trollagem" (trolling), ou seja, provocações e ofensas gratuitas a ponto de alterar emocionalmente um usuário é a maneira mais fácil de gerar uma flame war $^{16}$. Através da criação de perfil falso, o troll semeia o caos e a discórdia nas comunidades, quebrando toda e qualquer etiqueta. Só resta então à moderação expulsá-lo.

\footnotetext{
${ }^{16}$ Flame war ou guerra inflamada é a provocação deliberada por parte de um ou mais participante de grupos de discussão eletrônica, como a Usenet, listas de discussão via e-mail ou fóruns de internet com o intuito de desestabilizar emocionalmente a pessoa atacada, ou seja é uma troca de acusações on-line.
} 
Michel Maffesoli fala que "a existência de um grupo fundamentado num forte sentimento de pertença necessita, para a sobrevivência de cada um, que outros se criem a partir de uma exigência da mesma natureza”. (MAFFESOLI, 1987, p. 197). Com os fakes não é diferente, pois, apesar da proposta de anti-pertencimento do grupo é exatamente isso que une esse grupo e acaba criando uma rede de comunicação de contestação à rede de comunicação do Orkut, é que Maffesoli chamou de par "atração-repulsa". Afirmando que podemos notar em qualquer lugar grupamentos "que se apóiam na conciência, sutil mas enraizada, do sentimento de pertença e/ou do sentimento de diferença". (MAFFESOLI, 1987, p. 198).

Como o perfil é falso, os parceiros virtuais deste perfil geralmente são falsos também, tornando mais difícil o rastreamento do autor original. Tudo isso para agir de forma mais anônima possível. Os usuários podem fazer denúncias contra esses falsos perfis, mas as denúncias raramente atingem o seu objetivo, que seria o banimento do falso perfil do sistema. De qualquer forma, não adianta apagar o perfil falso, pois o autor original pode criar um novo a qualquer momento, e manter a ação subversiva da chamada comunidade fake.

Alguns entram em comunidades postando mensagens contrárias ao assunto, buscando chamar a atenção para si mesmos, criar confusões ou menosprezar os outros integrantes. E, como é possível postar mensagens anonimamente em algumas comunidades, alguns utilizam essa ferramenta para falar mal e humilhar os participantes delas, semear caos e discórdia. O Orkut pune essas pessoas, porém é difícil ter um controle de quem tem tais atitudes.

Alguns serviços oferecidos pelo Orkut nos ajudam a entender o quão importante é pertencer a algo, como por exemplo, o serviço “visitantes recentes". Consiste em mostrar na tela inicial as cinco últimas pessoas que visitaram seu perfil recentemente, e por conseqüência mostra os perfis que o usuário visitou. Se quiser uma navegação anônima para não aparecer no perfil das outras pessoas, o serviço pode ser desabilitado, assim ficará anônimo, mas isso fará que o usuário também não saiba quem foram as cinco últimas pessoas que visitaram recentemente seu perfil. Este serviço para alguns usuários é muito importante, pois ter seu perfil visitado é se sentir prestigiado pelo grupo reforçando seu sentimento de pertença ao grupo (MAFFESOLI, 1987).

Para outros, se manterem anônimos é mais importante do que saber quem visitou seu perfil, pois assim ele pode visitar vários perfis sem ser notado, é como navegar invisível. O mesmo usuário pode ter diferentes modos de agir com o mesmo perfil ou agir da mesma maneira em seus diversos perfis isso vai depender do daquilo que o usuário pretende em 
determinado momento, conforme Erving Goffman (1998) uma performance para cada footing.

Como referido anteriormente nesta pesquisa considerei como informantes predominantemente, porém não exclusivamente, as personas que estão a bailar no Orkut. As pessoas "físicas" existentes por trás destas personas, não foram ignoradas porque desde o principio eu queria ver a performance dos usuários no exato momento da interação com o sistema.

Para Goffman (1998), os fenômenos sociais se manifestam nas relações entre indivíduos, em encontros sociais que representam, em sua essência interacional, as estruturas sociais, culturais e políticas da sociedade à qual os interlocutores pertencem. Minha intenção era ter este contato olho no olho, ou como diria Goffman face to face, com o nativo em seu local de interação. Do modo que Malinowski nos ensinou lá em 1922 no clássico Argonautas do Pacífico Ocidental: um relato do empreendimento e da aventura dos nativos nos arquipélagos da Nova Guiné Melanésia. Através do método da observação participante o pesquisador deve largar seus instrumentos de pesquisa e participar ativamente dos eventos sociais, assim o pesquisador pode captar fenômenos que Malinowski chamou de imponderáveis da vida real e do comportamento típico, que devem ser registrados em seu diário de campo.

A observação participante desta pesquisa se realizou no ambiente do site Orkut na presença dos entrevistados. As entrevistas foram realizadas em locais públicos dois cibercafés, um na Avenida Otávio Rocha esquina com a rua Dr. Flores o outro no subsolo do Shoping Rua da Praia, duas lan-houses uma no segundo andar do Shoping Rua da Praia a outra na estação Mercado do Trensurb e no tele-centro do mercado público do centro de Porto Alegre. Realizei entrevistas on-line (via msn) com os fakes Dark Win e Sofrida Loren.

A convivência direta com os entrevistados me levou a verificar se havia algum (ou alguns) contexto sócio-econômico específico determinável que formasse o perfil dos mesmos, e se este aspecto (ou como este aspecto) influenciava o seu comportamento na interação com a comunidade Orkut. Quais as estratégias que essas pessoas lançam mão para participar tão ativamente da comunidade se havia a real dificuldade de não estarem com o computar disponível a qualquer hora do dia, quais os locais, horários e maneiras que essas pessoas realizavam suas interações. E, pensando nessas questões, resolvi adicionar esse recorte a gama de entrevistados a qual tinha recebido a confirmação de interesse em participar da pesquisa. $\mathrm{O}$ 
objetivo foi facilmente alcançado devido à exigência anterior, de fazer as entrevistas em locais públicos.

\section{Performances}

A estratégia de observar o usuário no exato momento em que ele está interagindo com seus "amigos" no Orkut, mostrou-se muito eficaz, pois, possibilitou-me a experiência de presenciar, nos termos de Goffman, o desempenho das identidades sociais e lingüísticas dos participantes engajados em uma situação de interação face to face mediada por computador. (GOFFMAN, 1998).

Observando Yago e Mariana, em entrevistas separadas, notei que em determinados momentos agiram de maneira similar, mas na maioria das vezes tiveram uma performance diferenciada um do outro. Mariana não aceita pedidos de "adicionar amigo" de quem ela não conhece pessoalmente, apesar de aceitar aqueles que ela conhece de vista, mas mesmo assim ela tem noção de quem é esta pessoa. Por sua vez Yago aceita qualquer um que faça o pedido. Em quanto Mariana se preocupa muito com seu perfil, alterando suas fotos por exemplo; Yago nem se refere as suas. Ao navegarem pelos perfis "alheios" tiveram uma performance bem similar ao que tange ao álbum de fotos de seus visitados, ambos ao visitarem qualquer perfil de quem quer que seja entraram nos álbuns de fotos e fizeram comentários conforme estas lhes agradavam ou não.

Qualquer relação social tem lugar num determinado enquadramento interativo, implicando que os sujeitos assumam determinadas convenções. Os sujeitos da relação social adaptam o seu comportamento a este enquadramento, aquilo que Goffman (1998) chamou de Footing a postura, o alinhamento, a posição dos interlocutores uns em relação aos outros, esclarecendo que a projeção do "eu” de cada indivíduo torna-se explícita e, portanto, visível e identificável no decorrer da interação. "Footings são introduzidos, negociados, ratificados (ou não), co-sustentados e modificados na interação”. (RIBEIRO; GARCEZ, 1998, p. 70).

Para Goffman (1998), o que vimos acima foram diferentes footings para diferentes enquadres, incluindo a participação do pesquisador na interação com seus entrevistados.

William Foote Whyte em sua obra Sociedade de Esquina nos mostra o quanto é importante para o pesquisador fazer parte da rede de relações de seus nativos, tanto que resolveu ir morar com uma família tradicional do bairro com o objetivo de se integrar o máximo possível na comunidade. 
Meu esforço em aprender a língua provavelmente foi mais útil para demonstrar a sinceridade de meu interesse do que qualquer coisa que eu pudesse ter dito às pessoas a meu respeito e de meu trabalho. Como poderia um pesquisador planejar "criticar nosso povo" quando se deu ao trabalho de aprender a língua? Com a língua vem a compreensão, e com certeza é mais fácil criticar as pessoas se você não as compreende. (WHYTE, 2005, p. 298).

O problema surge quando a interação se transforma em intervenção como aconteceu com comigo quando comecei a ensinar Mariana como interagir no Orkut no momento das trocas de fotos de seu álbum. Fato também ocorrido com William Foote Whyte na passagem que ele procura se reaproximar de Tony Cataldo tomou a decisão de apoiá-lo contra Carlos a respeito da realização de um comício no clube, o que acabou por afastar Tony mais uma vez de suas relações. Lição que nos ensina assim:

\begin{abstract}
Neste caso, violei uma regra fundamental da observação participante: busquei ativamente influenciar os eventos. Numa disputa tão acirrada e confusa, é bem provável que meu endosso à posição de Tony tenha sido um fator decisivo. [...] Mais tarde, pensando sobre esse evento, cheguei à conclusão de que minha ação não apenas havia sido imprudente, do ponto de vista prático da pesquisa, mas também uma violação da ética profissional. Não é justo com as pessoas que aceitam o observador participante que ele busque manipulá-Ias, possivelmente causando-Ihes algum prejuízo, somente para tentar fortalecer sua posição social numa determinada área. (WHYTE, 2005, p. 331).
\end{abstract}

Foi pensando nas palavras de William Foote Whyte que mesmo intervindo na performance de Mariana, procurei manter meu footing de pesquisador, reafirmando sempre a ela e a mim mesmo que mostraria o caminho mas ela é que deveria fazer as alterações de seu álbum. Em outro momento quando a máquina desligou mudei meu footing de observador passivo para agente ativo com o atendente do cibercafé.

Yago quando está interagindo no Orkut com seu fake "Fudêncio" (como vimos no capítulo 4) tem uma performance completamente diferente em relação ao seu perfil original, faz coisas que não faria se estivesse interagindo como Yago, mas como Fudêncio suas mudanças de footing são mais dinâmicas e pontuais. Para Goffman, o ator social tem a habilidade de escolher seu palco e sua peça, assim como o figurino que ele usará para cada público. O objetivo principal do ator é manter sua coerência e se ajustar de acordo com a situação. Isso é feito, principalmente, com a interação dos outros atores: “[...] em cada contexto da vida social os atores assumem papéis diferentes, e vivem esses papéis de forma consistente.” (GUIMARÃES JR., 2000, p. 18). 


\section{Conclusões}

Uma das premissas do trabalho etnográfico é dar conta do fenômeno social que envolve o objeto estudado como um fato etnográfico, descrevendo os dados com densidade conceitual, observando os fatos significativos não deixando fugir aos olhos do pesquisador o que está escondido por trás das aparências. Ao final do trabalho, a cada releitura de revisão, a sensação de que falta algo é angustiante. Mas, apreender um objeto de estudo com significados diversos dentro de um mundo totalmente novo, atravessado por tantos discursos especulativos, não constitui tarefa fácil.

O ciberespaço nos mostra que as pessoas estão se comunicando em uma espécie de jogo social, de rede interativa, se reunindo em novas formas de sociabilidade em um novo ambiente e por meio dele, criam vínculos, agem e participam de trocas no mundo social, ou devemos dizer mundo global? Pode-se identificar que é isto que as comunidades virtuais estão proporcionando uma reunião virtual, que pode ser tão boa e confortante em certos momentos, como uma reunião presencial, mas que mesmo tornando possível uma tribalização virtual, muitas das pessoas buscam outras que conhecem off-line para fortalecer estes laços criados no ciberespaço.

Uma das perguntas que fazia a todos que entrevistava nesta pesquisa era o porquê de entrar no Orkut e não em outro site de relacionamento, como o Gazzag, por exemplo, e a resposta que mais ouvia era de que nos outros não tinha ninguém e que todos estavam no Orkut. O diferencial deste site em relação aos outros é a ênfase nas imagens de seus usuários, para estes indivíduos é importante "ver" quem é a pessoa (persona) que está dividindo o espaço com ele é ter contato com sua foto ou seu avatar.

Acessar o Orkut diariamente, para Mariana, é estar em constante comunicação com as pessoas, para Yago é a melhor maneira de falar com seus amigos num curto espaço de tempo, para Claudiane é estar na "vitrine" é "ver" e ser "vista" por seus amigos. Para estes usuários, estar no Orkut é estar onde todos estão, é "não ficar de fora” é estar onde a "turma" está, é fazer parte deste local, deste grupo. (MAFFESOLI, 1987, 2000).

Este sentimento de pertença, esta necessidade de se comunicar é ainda mais forte em relações aos usuários que possuem perfis fakes, pois, a pessoa (persona), que representa diversos papéis e muda o seu figurino, conforme seus gostos e momentos tem a chance de participar de quantas tribos desejar, sua motivação a comunicação, a troca social nas novas formas de relacionamento e interação, permitindo um conforto psicológico de estar "ligado", 
de integrar redes de sociabilidade, de mostrar-se e de ser percebido numa complexa sociedade em suas formas mais simples de relações afetivas e de pertencimento social. Como sugere o sociólogo, é poder objetivamente ser subjetivo, é o estar-junto que se torna relevante (MAFFESOLI, 1987).

Este constante deslocamento em redes, grupos, formas de interações, orienta os possíveis papéis a serem performatizado, permitindo o que Goffman (1998) denomina de footing. Percorrer a rede deslocar-se nas interações que expressam a maneira como os usuários produzem e recebem as elocuções dos outros integrantes da interação, dentro de uma cadeia dinâmica de relações interativas que reproduzem as realidades sociais de cada interlocutor, esculpindo-as no momento interacional, dentro de sua rede de comunicação. Não há mistérios a serem desvendados, apenas perfomances e personagens a serem interpretados na boa tradição simmeliana (1939) para quem a comunicação é o cimento da sociedade, ou na herança maffesoliana (2000) para quem o corpo é o cimento da sociedade, ambos permitindo concluir que quem se comunica é o corpo feito de personagem, a persona, a pessoa, o indivíduo no mundo social.

As redes de comunicações se estruturam motivadas por sentimentos de afinidades e pelo prazer estético, de valorização da imagem, do presenteísmo, do prazer de compartilhar emoções coletivamente e da possibilidade de interação via tecnologias do imaginário se desenvolve e se manifesta no contato e na formação de grupos virtuais no ciberespaço, independente do tema de interesse que identifica e une cada grupo, que pode ser banal e/ou intelectual.

As questões levantadas aqui devem ser aprofundadas em futuras pesquisas. Os diferentes papéis interpretados pelos navegantes do ciberespaço, as relações estéticas dentro do ciberespaço e as abordagens teóricas para o entendimento deste novo mundo são os pontos que gostaria de deixar abertos para discussão.

\section{REFERÊNCIAS}

ABRANTES, Monique. Cibercultura. [200-]. Disponível em:

$<$ http://www.jornalistasdaweb.com.br/index guias.asp?Guia=cibercultura $>$. Acesso em 26 abril de 2004.

BOURDIEU, Pierre. Esboço de uma teoria da prática. In: ORTIZ, Renato (Org.). Pierre Bourdieu: Sociologia. São Paulo: Ática, 1983a. 
BOURDIEU, Pierre.. Questões de Sociologia. Rio de Janeiro: Marco Zero, $1983 b$.

BOURDIEU, Pierre.. Sociologia. 2. ed. São Paulo: Ática, 1994.

CASTELLS, Manuel. A sociedade em rede. São Paulo: Paz e Terra, 1999.

CEIA, Carlos. Alteridade. 2005. In: E-Dicionário de Termos Literários. Disponível em: $<$ http://www.fcsh.unl.pt/edtl/verbetes/A/alteridade.htm>. Acesso em 11 novembro de 2006.

COSTA, Márcia Regina da. Tribos urbanas, identidades e culturas juvenis. In ESPAÇO \& DEBATES: revista de Estudos Regionais e Urbanos. São Paulo: NERU, 2001.

DORNELlES, Jonatas. Planeta Terra, Cidade Porto Alegre uma etnografia entre internautas. 2003. 208 f. Dissertação (Mestrado em Antropologia Social) - Instituto de Filosofia e Ciências Humanas, Universidade Federal do Rio Grande do Sul, Porto Alegre, 2003.

FARIAS, Priscila; CANTONI, Rejane. Fora do Corpo. In: LEÃO, Lúcia (Org.) Interlab: Labirintos do pensamento contemporâneo. São Paulo: Iluminuras, 2002. p. 207 - 217.

FOUCAULT, Michel. História da sexualidade: A vontade de saber. 14 ${ }^{\mathrm{a}}$. ed. Rio de Janeiro: Graal, 2001.

FOUCAULT, Michel. História da sexualidade: O cuidado de si. Rio de Janeiro: Graal, 1985.

GOFFMAN, Erving. A Representação do eu na vida cotidiana. Petrópolis: Vozes, 1975.

GOFFMAN, Erving. Estigma: notas sobre a manipulação da identidade deteriorada. Rio de Janeiro: J. Zahar, 1980.

. Footing. In: RIBEIRO, Branca Telles e GARCEZ, Pedro M. (Org.)

Sociolingüística Interacional. Porto Alegre: AGE, 1998. p. 70 - 97.

GUIMARÃES, Alba Zaluar (Org.). Desvendando máscaras sociais. 3. ed. Rio de Janeiro: Livraria Francisco Alves, 1990.

GUIMARÃES Jr., Mário J.L. A Cibercultura e o surgimento de novas formas de sociabilidade. In: Imprimatur, Revista Eletrônica de Ciências Humanas, 1997. Disponível em: <http://www.cfh.ufsc.br/imprimatur/artigos/guimaraes.htm>. Acesso em 26 abril de 2004.

GUIMARÃES Jr., Mário J.L.. Etnografia em ambientes de sociabilidade virtual multimídia. In: X Ciclo de Estudos sobre o Imaginário - Imaginário e Cibercultura. Recife, 1998. Disponível em: <http://www.cfh.ufsc.br/ guima/academia.html \#trabalhos $>$. Acesso em 26 abril de 2004.

GUIMARÃES Jr., Mário J.L..Sociabilidade no Ciberespaço: Distinção entre Plataformas e Ambientes. In: 51 a Reunião Anual da SBPC, Porto Alegre, 1999a. Disponível em: $<$ http://www.cfh.ufsc.br/ guima/papers/plat_amb.html>. Acesso em 26 abril de 2004.

GUIMARÃES Jr., Mário J.L.. O Ciberespaço como Cenário para Ciências Sociais. In: IX Congresso Brasileiro de Sociologia, Porto Alegre, 1999b. Disponível em: $<$ http://www.cfh.ufsc.br/ guima/papers/ciber_cenario.html $>$. Acesso em 26 abril de 2004.

GUIMARÃES Jr., Mário J.L.. Vivendo no Palace: Etnografia de um ambiente de sociabilidade no Ciberespaço. 2000. 149 f. Dissertação (Mestrado em Antropologia Social) CFH, Universidade Federal de Santa Catarina, Florianópolis, 2000.

GUIMARÃES Jr., Mário J.L.. De pés descalços no ciberespaço: Tecnologia e cultura no cotidiano de um grupo social on-line. In: Revista Horizontes Antropológicos , nº 21, PPGAS, Editora da UFRGS: Porto Alegre, 2004. p. 123 - 154.

LEÃO, Lúcia (Org.) Interlab: Labirintos do pensamento contemporâneo. São Paulo: Iluminuras, 2002.

LEMOS, André. Cibercultura: Tecnologia e vida social na cultura contemporânea. Porto Alegre: Sulina, 2004.

LÉVY, Pierre. O que é o virtual?. São Paulo: Editora 34, 1998. 
LÉVY, Pierre. A Inteligência coletiva: por uma antropologia do ciberespaço. São Paulo: Edições Loyola, 1999a.

LÉVY, Pierre. Cibercultura. São Paulo: Editora 34, 1999 b.

MAFESSOLI, Michel. O tempo das tribos: o declínio do individualismo nas sociedades de massas. Rio de Janeiro: Forense-Universitária, 1987.

MAFESSOLI, Michel.. No Fundo das Aparências. Petrópolis: Vozes, 1996.

MAFESSOLI, Michel.. A Comunicação sem fim (teoria pós-moderna da comunicação). In: Revista FAMECOS: mídia, cultura e tecnologia, $\mathrm{n}^{\mathbf{0}}$ 20, Porto Alegre: Faculdade de Comunicação Social, PUCRS, 2003. p. 13 - 20.

As mascaras do corpo. In: Líbero: revista acadêmica de pósgraduação, Ano III, VOL. 3, nº 6. São Paulo: Fundação Cásper Líbero, 2000. p.44 - 49.

MAUSS, Marcel. Sociologia e Antropologia. São Paulo: Edusp/EPU, 1974.

MORAES FILHO, Evaristo de (Org). Georg Simmel: sociologia. São Paulo: Editora Ática, 1983.

RABELO, Mirian Cristina; Alves, Paulo César. Corpo, experiência e cultura. In: XXV Encontro Anual da ANPOCS, Caxambu, [S. n.], 2001, p. 1-20.

RIBEIRO, Branca Telles; GARCEZ, Pedro M. (Org.) Sociolingüística Interacional. Porto Alegre: AGE, 1998.

SANTAELLA, Lucia. Cultura tecnológica \& o corpo cibernético. In: LEÃO, Lúcia (Org.) Interlab: Labirintos do pensamento contemporâneo. São Paulo: Iluminuras, 2002. p. 197 206.

SANTOS, Alckmar Luiz dos. Leituras de nós: ciberespaço e literatura. São Paulo: Itaú Cultural, 2003

SAYÃO, Yara; BOCK, Sílvio Duarte. Matrizes da Sexualidade, 2002. Disponível em: $<$ http://www.educarede.org.br/educa/oassuntoe/index.cfm?

pagina=interna\&id_tema=8\&id_subtema=6>. Acesso em 05 junho de 2005.

SILVEIRA, Fernando de Almeida; FURLAN, Reinaldo. Corpo e Alma em Foucault: Postulados para uma Metodologia da Psicologia, 2005. Disponível em: $<$ http://www.scielo.br/scielo.php?pid=S0103-65642003000300012\&script=

sci_arttext\&tlng=pt>. Acesso em 05 junho de 2005.

SIMMEL, Georg. A metrópole e a vida mental. In VELHO, Otávio G. (Org). O fenômeno urbano. Rio de Janeiro: Zahar, 1967.

SIMMEL, Georg. A natureza sociológica do conflito. In: MORAES FILHO, Evaristo de (Org). Georg Simmel: sociologia. São Paulo: Editora Ática, 1983, p. 122 - 134.

SIMMEL, Georg. Sociabilidade - um exemplo de sociologia pura ou formal. In: MORAES FILHO, Evaristo de (Org). Georg Simmel: sociologia. São Paulo: Ática, 1983, p. 165 - 181.

FILHO, Evaristo de (Org). Sociologia: estudios sobre las formas de socialización. Buenos Aires: Espasa-Calpe, 1939.

WHYTE, Willian Foote. Sociedade de esquina. Rio de Janeiro: J. Zahar, 2005.

VELHO, Gilberto. Projeto e Metamorfose, antropologia das sociedades complexas. Rio de Janeiro: J. Zahar, 1994.

VELHO, Gilberto. Individualismo, Anonimato e Violência na Metrópole. In: Revista Horizontes Antropológicos no 13. Porto Alegre: Editora da UFRGS, 2000, p. 15 - 30.

VELHO, Gilberto . Antropologia Urbana: Tradição e modernidade na cidade brasileira. 1984. Disponível em: <http://www.tropicologia.org.br/conferencias.html>. Acesso em: 20 setembro de 2005.

VELHO, Otávio G. (Org). O fenômeno urbano. Rio de Janeiro: Zahar, 1967. 


\section{Páginas da Internet Utilizadas na Pesquisa}

http://pt.wikipedia.org

http://secondlife.com/

http://www.educare.org.br

http://www.google.com.br

http://www.gruposecondlife.com.br/

https://www.orkut.com

http://www.scielo.br 